\title{
Alterações na morfologia e na viabilidade no desenvolvimento de embriões bovinos fecundados in vitro com sêmen contaminado experimentalmente à Escherichia coli produtora da toxina Shiga stx2
}

\author{
Changes in morphology and viability on the development of bovine \\ embryos in vitro fertilized with experimentally contaminated semen \\ to Escherichia coli Shiga toxin producing stx2
}

\author{
Mariana Moraes Piccolomini ${ }^{1 *}$, Ana Carolina Goes ${ }^{1}$, Marcia Catroxo', \\ Simone Miyashiro', Alessandra Figueiredo de Castro Nassar' ${ }^{1}$, Magali D 'Angelo'
}

\begin{abstract}
RESUMO: O objetivo deste trabalho foi avaliar, por meio de microscopia óptica e eletrônica de transmissão, as alteraçôes na morfologia e a viabilidade do desenvolvimento de embrióes bovinos fecundados com sêmen contaminado experimentalmente à Escherichia coli produtora da toxina shiga stx2 (STEC). Para tanto, oócitos foram aspirados de ovários de vacas abatidas e selecionados para maturaçáo in vitro. Após 20-24 horas de maturaçáo, os oócitos foram divididos em 2 grupos. Sendo o primeiro grupo o controle $(\mathrm{n}=418)$, fertilizado com sêmen testado e sem nenhum tipo de contaminante e o segundo, o grupo contaminado $(\mathrm{n}=415)$, fertilizado com sêmen exposto a STEC. Cada sêmen foi tratado pela técnica de gradiente descontínuo de Percoll. Após o período de fecundação, os embriōes foram avaliados quanto a sua morfologia e viabilidade, com o auxílio da microscopia óptica e eletrônica. Na avaliaçáo morfológica, os oócitos fecundados com o sêmen contaminado apresentaram retração citoplasmática, falhas na divisão, assimetria de blastômeros, ooplasma granuloso, coloração castanho-escuro, formação de vacúolos, degeneração e rompimento da zona pelúcida. Essas alteraçôes não foram observadas no grupo controle. A avaliação de todos oócitos incluídos mostrou taxas de clivagem de 70,3 e 52,8\%, respectivamente, para embriōes controle e contaminado ( $\mathrm{p}=0,0001)$. Após o $5^{\circ}$ dia de desenvolvimento embrionário foram observadas $44,7 \%$ de mórulas no grupo controle e $22,4 \%$ no grupo contaminado, apresentando diferença significativa $(\mathrm{p}=0,0001)$. A presença da STEC interfere na taxa de clivagem dos embrióes e também inviabiliza e provoca queda no desenvolvimento embrionário ao estádio de mórula, além de causar alteraçôes morfológicas durante esse desenvolvimento.
\end{abstract}

PALAVRAS-CHAVE: sêmen bovino; Escherichia coli produtora da shiga toxina stx2; produção in vitro; microscopia eletrônica de transmissão.

\begin{abstract}
The objective of this study was to evaluate by optical microscopy and transmission electron, changes in morphology and viability of the development of bovine embryos, fertilized with semen experimentally contaminated (STEC). Oocytes were aspirated from ovaries of slaughtered cows and the intact zona pellucida were selected and matured. After 20-24 hours of maturation, the oocytes were divided into 2 groups. The first, control group $(\mathrm{n}=418)$, fertilized with semen tested and without any type of contaminant and the second, the infected group $(\mathrm{n}=415)$, fertilized with sperm exposed to STEC. Both semen were treated by the technique of discontinuous Percoll gradient. After the period of fertilization, embryos were evaluated for their morphology and viability by optical and electron microscopy. In morphologic evaluation, the oocytes fertilized with contaminated semen showed cytoplasmic shrinkage, gaps in the division, asymmetry of blastomeres, ooplasm grainy, dark brown color, vacuoles formation, degeneration and zona pellucid disruption. These changes were not observed in the control group. The cleavage rate was 70.3 and $52.8 \%$, respectively, for control and infected groups, significant differences $(\mathrm{p}=0.0001)$. After the $5^{\text {th }}$ day of embryonic development, where it was observed $44.7 \%$ of morula in the control group, and $22.4 \%$ in the contaminated group, showing a significant difference $(p=0.0001)$. The presence of STEC interferes with the cleavage rate of embryos and also prevents and causes a decline in embryonic development to the morula stage and cause morphological changes during this development.
\end{abstract}

KEYWORDS: bovine semen; Escherichia coli shiga toxin-producing stx2; in vitro fertilization; transmission electron microscopy.

\footnotetext{
'Centro de Pesquisa e Desenvolvimento de Sanidade Animal; Instituto Biológico - São Paulo (SP), Brasil.

*Autor correspondente: mariola_mmp@hotmail.com

Recebido em: 15/01/2013. Aceito em: 28/01/2015
} 


\section{INTRODUÇÃO}

Embora cada vez mais utilizadas, as técnicas de reproduçáo assistida ainda necessitam de pesquisas que avaliem os riscos sanitários das doadoras, dos oócitos e dos embriōes (MAGAJEvsKI, 2007). É importante e necessário o aprimoramento contínuo de métodos de controle sanitário do rebanho e das biotécnicas ligadas à reprodução, uma vez que as mortalidades embrionária e fetal têm um grande impacto na rentabilidade de qualquer sistema de produção animal.

A contaminação do sêmen pode alterar suas características, tendo uma ação direta no espermatozoide, e também pode infectar a fêmea, resultando assim, em baixas taxas de concepção. Muitos micro-organismos podem se localizar na cavidade prepucial, na pele e mesmo no solo, de modo que a contaminação do sêmen pode ocorrer na hora da colheita (Costa; Prado, 2008).

D'ANGELO et al. (2006), após relatarem contaminação de embrióes produzidos in vitro por amostras de sêmen contaminadas com: Acinetobacter spp. (5.000 unidades formadoras de colônia - UFC/mL), Enterobacter aerogenes $(5.000 \mathrm{UFC} / \mathrm{mL})$, Escherichia coli (E. coli) $(5.000 \mathrm{UFC} / \mathrm{mL})$, Streptococcus spp. (incontáveis $/ \mathrm{mL}$ ) e Alcaligenes faecalis (incontáveis $/ \mathrm{mL}$ ), concluíram que a amostra de sêmen deve ser isenta de contaminantes, pois a condição in vitro promove ambiente favorável para o seu crescimento.

A presença de bactérias no sêmen torna o procedimento de produção in vitro (PIV) inviável quando a concentração de micro-organismos é alta. Quando a concentração é baixa, sua presença não será facilmente detectada, uma vez que pode não afetar a fecundaçáo e o desenvolvimento dos embriôes e, portanto, retardar a aplicaçáo de medidas de controle, podendo facilitar a disseminação do agente (STRINGFELLOW; Givens, 2000).

A E. coli produtora de toxina Shiga (STEC) é encontrada no intestino de animais sadios, sendo o gado bovino principal reservatório, e também no meio ambiente, no qual os animais são mantidos (FENG, 2000). Possui resistência às condiçóes desfavoráveis do meio ambiente, podendo sobreviver por mais de dez meses (Varma et al., 2003).

O Ministério da Agricultura, Pecuária e Abastecimento (MAPA) tem discutido a obrigatoriedade da realização de espermocultura de cada partida de sêmen industrializado, em função das frequentes falhas na PIV, devido às contaminaçôes dos oócitos com bactérias ubiquitárias e oportunistas da microbiota prepucial (CARVALHO et al., 2007).

Dessa forma, torna-se relevante a avaliação da infectividade e o efeito em embrióes produzidos com sêmen contaminado com STEC, para podermos subsidiar a proposta de que o sêmen precisa ser isento de qualquer micro-organismo, sendo ele patogênico ou não. Alguns desses micro-organismos podem náo acarretar doenças para fêmea receptora ou causar disseminaçáo para o rebanho, mas podem comprometer a técnica de reproduçáa, causando, também, prejuízos ao produtor.

Este trabalho teve como objetivo avaliar, por meio de microscopia óptica e eletrônica de transmissão, as alterações na morfologia e a viabilidade do desenvolvimento de embriôes bovinos fecundados com sêmen contaminado experimentalmente a STEC.

\section{MATERIAL E MÉTODOS}

Foi utilizada, para contaminação do sêmen, a bactéria STEC isolada de bovinos em abatedouros do estado de São Paulo (SP), por swab retal e da carcaça, logo após o abate, identificada por meio da reação em cadeia da polimerase (PCR), apresentando o gene responsável pela produção da toxina stx2 (Miyashiro et al., 2009). Sua suspensão foi preparada na concentração de 200 UFC.

Os ovários foram colhidos em abatedouro de Sáo José dos Campos (SP) e mantidos em solução salina com 1\% de antibióticos (Gentamicina). O procedimento acima foi aprovado pelo Comtê de Ética em Experimentação Animal do Instituto Biológico - CETEA-IB, (protocolo no 40/08). Foram necessárias duas idas ao abatedouro para coleta de ovários que foram analisados quanto à presença de E. coli, e somente o líquido folicular que estava sem contaminação foi utilizado.

Os folículos ovarianos foram aspirados e os oócitos foram selecionados e maturados em gotas de $100 \mu \mathrm{L}$ meio de maturação (MIV - In Vitro ${ }^{\circledR}$ ), em placa de Petri, na qual permaneceram por 20 horas em estufa à temperatura de $38^{\circ} \mathrm{C}, 5 \%$ de $\mathrm{CO}_{2}$ e $90 \%$ de umidade. Foram selecionados apenas os oócitos que apresentavam células da granulosa, com ou sem expansão, para maturação. Foram mantidos até 20 oócitos por gota.

Para cada procedimento de fecundação in vitro (FIV), foram descongeladas, em temperatura de $37^{\circ} \mathrm{C}$, por 30 segundos, duas palhetas de sêmen da mesma partida de um mesmo touro (Central Bela Vista/Genética Bovina). Sendo uma utilizada como sêmen controle e outra como contaminado, exposto a 200 UFC de E. coli. A amostra foi contaminada logo após o descongelamento da palheta e incubada durante 30 minutos em estufa a temperatura de $38^{\circ} \mathrm{C}, 5 \%$ de $\mathrm{CO}_{2}$ e $90 \%$ de umidade, em um tubo de microcentrífuga. O grupo controle também foi mantido durante 30 minutos na incubadora após o descongelamento. Após a exposição, as amostras de sêmen foram submetidas, separadamente, à técnica de gradiente descontínuo de Percoll ${ }^{\oplus}$, para separar o plasma seminal, células, debris e espermatozoides imóveis; dessa forma, selecionamos apenas os espermatozoides de melhor qualidade. A concentração espermática foi ajustada em aproximadamente 100 mil espermatozoides móveis para cada oócito, antes de ser colocada na placa de fecundaçáo, 
com gotas de $100 \mu \mathrm{L}$ de meio de fecundação (In Vitro ${ }^{\circledR}$ ). Os oócitos maturados foram transferidos para essas novas gotas (até 20 por gota) em grupos separados.

Após 18 horas da fecundação, os presumíveis zigotos foram transferidos para nova placa com gotas de $100 \mu \mathrm{L}$ de meio Synthetic Oviduct Fluid - SOF (In Vitro ${ }^{\circledR}$ ), mantendo 20 por gota. As células da granulosa foram retiradas e as placas levadas à estufa a $38^{\circ} \mathrm{C}, 5 \%$ de $\mathrm{CO}_{2}$ e $90 \%$ de umidade até o $5^{\circ}$ dia de desenvolvimento, trocando-se o meio no $3^{\circ}$ dia. Foram feitas observaçóes para análise morfológica, por meio de possíveis alteraçôes, como retração citoplasmática, assimetria de blastômeros, ooplasma granuloso, coloração castanho-escuro, vacúolos, degeneraçấo e rompimento da zona pelúcida. Também foi observada a viabilidade embrionária, por intermédio da taxa de clivagem e do desenvolvimento, verificando o número de células até o $5^{\circ}$ dia de desenvolvimento, na presença ou ausência do patógeno. Para análise estatística da taxa de clivagem dos embrióes, foi utilizado o teste do $\chi^{2}$ com correçâo de Yates, sendo o nível de significância de $\mathrm{p}<0,05$.

No $3^{\circ}$ dia de desenvolvimento, alguns embrióes (50 de cada grupo) foram fixados, colocados em resinas e cortados com ultramicrótomo em corte semifino $(2 \mu \mathrm{m})$, sendo levados para análise ultraestrutural os blocos em que foram seccionados e os cortes ultrafinos recolhidos e fixados em telas de níquel (Knutton, 1995; Padrón, 1998). As telas foram examinadas em microscópio eletrônico de transmissão Philips EM208.

É importante ressaltar que os meios de cultivo utilizados eram acrescidos de antibiótico (sulfato de gentamicina $50 \mathrm{mg} / \mathrm{L}$ ).

Este trabalho foi realizado de acordo os princípios éticos da experimentação animal estabelecidos pela CETEA-IB, conforme consta em declaração de 23 de abril de 2008.

\section{RESULTADOS}

Para a análise morfológica e da taxa de clivagem dos embrióes, foram identificados e selecionados 833 oócitos de 154 ovários, sendo 418 oócitos fecundados com sêmen controle e 415 oócitos fertilizados com sêmen exposto à STEC.

A avaliaçáo da viabilidade foi verificada por alteraçóes na taxa de clivagem dos embrióes e a taxa de desenvolvimento embrionário dos dois grupos pode ser observada conforme Tabela 1. De acordo com o teste do $\chi^{2}$, verificou-se que houve diferença significativa na taxa de clivagem $(p=0,0001)$ entre os embrióes dos grupos controle e contaminado. Isso implica que, possivelmente, a presença da bactéria no sêmen interferiu na clivagem dos embriôes. Após o $5^{\circ}$ dia de desenvolvimento embrionário também houve diferença significativa entre os dois grupos $(\mathrm{p}=0,0001)$. A presença da bactéria pode ter influenciado esse resultado, pela açăo direta sobre o espermatozoide e/ou embriáo, ou indireta, pela açâo de sua toxina ou por competir pelo mesmo substrato do embriáo.
A análise morfológica dos embrióes demonstrou muitas diferenças entre os embrióes dos dois grupos, como retração citoplasmática, falhas na divisão, assimetria de blastômeros, ooplasma granuloso, com coloraçáo castanho-escuro, formação de vacúolos, degeneração e rompimento da zona pelúcida no grupo contaminado.

Com o auxílio da microscopia óptica de corte semifino, foram observadas células granulosas e vacuolizadas, apresentando estruturas semelhantes às da E. coli (Fig. 1). A avaliação ultraestrutural com o auxílio de microscópio eletrônico de transmissão também mostrou que o grupo contaminado com E. coli apresentava alta formação de vacúolos e granulação no ooplasma, além de confirmar presenças de estruturas semelhantes às da $E$. coli no embriáo (Fig. 2). Esses resultados indicam que, apesar da utilização da técnica de gradiente descontínuo de Percoll $^{\circledR}$, a E. coli permaneceu nos meios e os espermatozoides atuaram como vetor para a transmissão desse patógeno. A presença do patógeno alterou morfologicamente o embrião, podendo prejudicar o seu desenvolvimento até a fase de blastocisto.

Tabela 1. Desenvolvimento embrionário dos grupos controle e contaminado. São Paulo (SP), 2009.

\begin{tabular}{|cccc} 
& Controle & Contaminado & Valor $\mathbf{p}$ \\
\hline \multirow{2}{*}{ Taxa de clivagem } & $70,3 \%$ & $52,8 \%$ & \\
& $(294 / 418)$ & $(219 / 415)$ & 0,0001 \\
\hline \multirow{2}{*}{ Taxa de mórulas } & $44,7 \%$ & $22,4 \%$ & 0,0001 \\
& $(187 / 418)$ & $(93 / 415)$ & \\
\hline
\end{tabular}

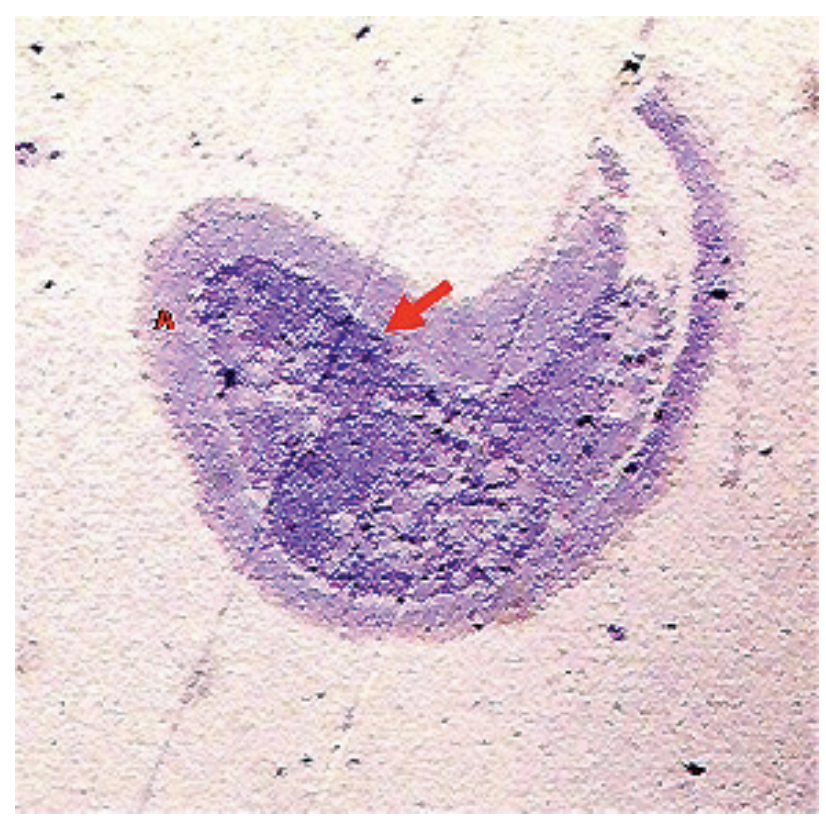

Figura 1. Embrião do grupo contaminado após o $4^{\circ}$ dia de desenvolvimento em microscopia óptica de corte semifino (aumento de 100x). (A) Zona pelúcida. Estruturas semelhantes às da $E$. coli estão representadas pela seta. 


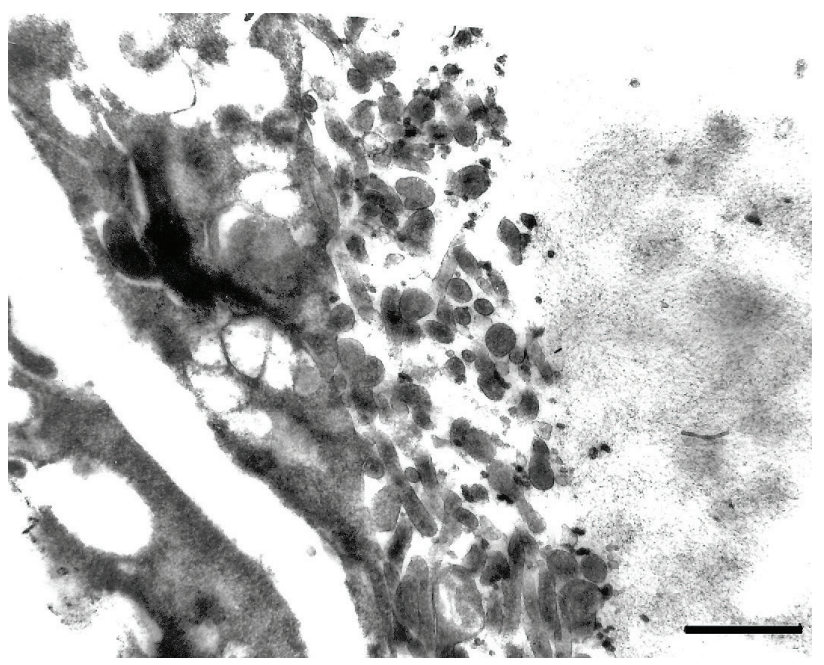

Figura 2. Embrião do grupo contaminado após o $4^{\circ}$ dia de desenvolvimento em microscopia eletrônica de transmissão (aumento de 10.000x). (A) Zona pelúcida. (B) Citoplasma. As setas indicam estruturas semelhantes às da bactéria.

\section{DISCUSSÃO}

Como pôde ser observado em nossos resultados, a taxa de clivagem alcançada para o grupo controle $(70,3 \%)$ foi equivalente às taxas encontradas em uma PIV comercial. Foram relatadas, em alguns estudos, taxas de 52\% (Saliba; Alvim, 2005), 61,5\% (Pfeifer et al., 2005), 67,2\% (Jasmin et al., 2005), 70,33\% (Iguma et al., 2005) e 82,1\% (Martins Junior et al., 2004). A taxa de clivagem observada no grupo contaminado (52,8\%) foi baixa, comparada com o grupo controle e com esses estudos. Por meio da análise estatística foi observada diferença significativa entre os grupos. Isso implica que, possivelmente, a presença da bactéria no sêmen interferiu na fecundação.

Bielanski (1997), ao contrário dos resultados apresentados, não observou diferença significativa na taxa de clivagem entre embrióes fecundados com sêmen controle (60\%) e embrióes fecundados com sêmen exposto experimentalmente ao Campylobacter fetus subsp venerealis (10 g organis$\mathrm{mos} / \mathrm{mL})(52 \%)$.

Piccolomini et al. (2008) infectaram experimentalmente embrióes murinos com E. coli produtora da toxina shiga stx 1 , antes da primeira divisão embrionária. Foi verificada taxa de clivagem de 53,8\% para o grupo controle e de 39,7\% para o grupo contaminado, também não apresentando significância nos resultados.

De acordo com Diemer et al. (1996) e Auroux et al. (1991), a E. coli apresenta um efeito direto sobre a motilidade progressiva da célula espermática; no entanto, esse efeito é dependente da concentração bacteriana. Del Porto et al. (1975) observaram que a concentração de 106 UFC por $\mathrm{mL}$ de sêmen causava uma queda significativa na motilidade espermática. Contraditoriamente, Edmondson et al. (1948) não encontraram qualquer correlação entre o número de bactérias presentes no sêmen bovino e o período de tempo que tal fluido apresentava células móveis. No entanto, observaram que fatores de virulência bacteriana, como capacidade hemolítica, estavam relacionados à diminuição da motilidade espermática.

Após o $5^{\circ}$ dia de desenvolvimento embrionário foram observadas $44,7 \%$ de mórulas no grupo controle e apenas $22,4 \%$ no grupo contaminado, havendo diferença significativa entre os dois grupos. A presença da bactéria pode ter influenciado esse resultado, pela ação direta sobre o espermatozoide e/ou embriáo, ou indireta, pela ação de sua toxina ou por competir pelo mesmo substrato do embriáo. BIELANSKI (1997) não observou diferença significativa em embrióes que se desenvolveram até a fase de blastocisto (31\% grupo contaminado e $41 \%$ grupo controle) com o sêmen exposto experimentalmente ao Campylobacter fetus subsp venerealis (10 g organismos/mL).

Pela análise morfológica dos embrióes, muitas diferenças foram observadas após o $4^{\circ}$ dia de desenvolvimento, como retração citoplasmática, falhas na divisão, assimetria de blastômeros, ooplasma granuloso, com coloração castanho-escuro, formação de vacúolos, degeneração e rompimento da zona pelúcida no grupo contaminado. Alteraçóes semelhantes em embriôes murinos expostos experimentalmente à $E$. coli produtora da toxina shiga stx 1 foram observadas por PicCOLOMINI et al. (2008), porém nenhum embrião apresentou rompimento da zona pelúcida.

$\mathrm{Na}$ análise dos embrióes, com o auxílio de microscopia óptica de corte semifino e eletrônica de transmissão, foram observadas células granulosas e vacuolizadas apresentando estruturas semelhantes às da $E$. coli inseridas no ooplasma. Esses resultados indicam que o espermatozoide pode atuar como vetor para a transmissão desse patógeno.

Stringfellow et al. (1997) descreveram um caso de uso acidental de sêmen contaminado criopreservado com Pseudomonas maltophilia na PIV de bovinos. Apesar do tratamento do sêmen por gradiente de Percoll $^{\circledR}$ e da adição de antibióticos nos meios utilizados para PIV, a bactéria persistiu nos meios de cultivo e causou degeneração dos embriōes.

Amostras de sêmen de touros persistentemente infectadas com o vírus da Diarréia Viral Bovina (BVDV) foram submetidas a técnicas de seleção de espermatozoides normalmente utilizados antes da PIV (swim up e gradiente de Percoll $^{\circledR}$ ) para determinar se essas técnicas selecionariam espermatozoides livres de BVDV. Utilizando a técnica de imunoperoxidase, foi verificado que todos os testes foram positivos para o BVDV, demonstrando que os métodos físicos comumente utilizados para preparação do sêmen não removem completamente os vírus. Esse sêmen foi utilizado para a PIV, e as taxas de clivagem e desenvolvimento para o estágio de blastocisto do grupo experimental foram inferiores aos do grupo controle. (BIELANSKI; JordAN, 1996)

D'ANGELO et al. (2006) relataram contaminação de embrióes de PIV por amostras de sêmen contaminadas com Acinetobacter 
$\operatorname{spp}(5.000 \mathrm{UFC} / \mathrm{mL})$, Enterobacter aerogenes $(5.000 \mathrm{UFC} / \mathrm{mL})$, E. coli (5.000 UFC/mL), Streptococcus spp (incontáveis/mL) e Alcaligenes faecalis (incontáveis $/ \mathrm{mL}$ ). A presença dessas bactérias no sêmen tornou o procedimento da FIV inviável.

Devido ao grande desenvolvimento tecnológico ocorrido nesses últimos anos em relação às técnicas empregadas na PIV de embriôes bovinos, do ponto de vista epidemiológico, deve-se ressaltar que, a cada fase de desenvolvimento, criam-se novos desafios em relaçáo ao controle de doenças. Conforme as tecnologias vão se tornando mais complexas, como no caso da injeção intracitoplasmática de espermatozoide (ICSI) e da clonagem, criam-se novas oportunidades para a introdução de patógenos no sistema (Stringfellow; ET AL. 2004). Portanto, a introdução de agentes infecciosos e oportunistas por meio da PIV é óbvia e, consequentemente, pesquisas sobre os riscos de transmissão de doenças por embriôes são de extrema importância, assim como pesquisas que visam o melhoramento das técnicas de PIV para aumentar cada vez mais as taxas de blastocistos e de sucesso na transferência de embrióes.

Para a biotécnica de PIV, devem ser revistas as normas de coleta, processamento e armazenamento de sêmen, para garantir que o fluido seja isento de micro-organismos. As boas práticas na coleta e no laboratório durante o processamento e armazenamento são fundamentais, uma vez que o muco prepucial possui uma microbiota normal muito rica, além de micro-organismos oportunistas, sendo um risco potencial para contaminação do sêmen. É importante ressaltar que os meios de cultivo utilizados durante a fertilizaçáo in vitro são ricos em nutrientes e tornam-se propícios ao desenvolvimento de contaminantes.
A boa higienização do prepúcio do touro e dos materiais utilizados durante a coleta, com descontaminantes adequados, é de extrema importância, assim como o uso de antibióticos eficientes durante a diluição do sêmen, já que o procedimento utilizado durante a FIV $\left(\right.$ Percoll $\left.{ }^{\circledR}\right)$ e meios de cultura acrescidos de antibióticos não se mostraram eficazes para reduzir ou eliminar a STEC.

\section{CONCLUSÃO}

Com base nos resultados apresentados, pode-se concluir que a presença da STEC interfere na taxa de clivagem dos embrióes e também provoca queda no desenvolvimento embrionário ao estádio de mórula, além de causar alteraçôes morfológicas durante esse desenvolvimento. $\mathrm{O}$ sêmen contaminado pode atuar como vetor para a transmissão desse patógeno.

\section{AGRADECIMENTOS}

À Coordenação de Aperfeiçoamento de Pessoal de Nível Superior (CAPES), ao Laboratório de Biologia Celular, Bacteriologia Geral e de Microscopia Eletrônica do Instituto Biológico, ao abatedouro Mantiqueira, localizado em São José dos Campos (SP), à Empresa In Vitro Brasil è̀ Central Bela Vista/Genética Bovina.

| | | | | | | | | | | | | | | | | | | | | | | | | | | | | | | | | | | | | | | | | | | | | | | | | | | | | | | | | | | | | | | | | | | | | | | | | | | | | | | | | | | | | | | | | | | | | | | | | | | | | | | | | | | | | | | | | | | | | | | | | | | | | | | | | | | | | | | | | | | | | | | | | | | | | | | | | | | | | | | | | | | | | | | | | | | | | | | | | | | | | | | | | | | | | | | | | | | | | | | | | | | | |

\section{REFERÊNCIAS}

AUROUX, M.R.; JACQUES, L.; MATHIEU, D. Is the sperm bacterial ratio a determining fator in impairment of sperm motility: in vitro study in man with Escherichia coli. International Journal of Andrology, v.14, n.4, p.264-270, 1991.

BIELANSKI, A.; JORDAN, L. Washing or washing and trypsin treatment is ineffective for removal of noncytopathic bovine viral diarrhea virus from bovine oocytes or embryos after experimental viral contamination of an in vitro fertilization system. Theriogenology, v. 46, p.1467-1476, 1996.

BIELANSKI, A. A review on disease transmission studies in relationship to production of embryos by in vitro fertilization and to related new reproductive technologies. Biotechnologies Advances, v.15, n.3-4, p.633-656, 1997.

CARVALHO, A.F.; SARAGÓ, A.; TELLES, F.M.; AZEVEDO, S.S.; BATISTA, C.S.A.; CAMPOS, F.R.; SCARCELLI, E.; GENOVEZ, M.E. Nova proposta de análise bacteriológica quantitativa aplicada a sêmen industrializado de touros para emprego em centrais de inseminação artificial. Biológico, v.69, n.2, p.113-198, 2007.
COSTA, J., P. PRADO, F., R., A. Avaliação bacteriológica do sêmen coletado de forma in natura de touros Nelore. Veterinária $e$ Zootecnia, v.15, n.2, supl.1, p.125, 2008.

D’ANGELO, M.; GALUPPO, A.G.; MELO, G.M.; PAVÃO, D.L.; ROJAS, N.; SOUZA, R.J.; ATHAYDE, C.; PINHEIRO, E.S. Acceptable microorganismos concentration in a sêmen sample for in vitro embryo production. Brazilian Journal of Microbiology, v.37, n.4, 2006.

DEL PORTO, G.B.; DERRICK JR, F.C.; BANNISTER, E.R. Bacterial effect on sperm motility. Urology, v.5, n.5, p.638-639, 1975.

DIEMER, T; WEIDNER, W.; MICHELMANN, H.W. Influence of Escherichia coli on motility parameters of human spermatozoa in vitro. International Journal of Andrology, v.19, n.5, p.271277, 1996.

EDMONDSON, J.E., TALLMAN, K.L., HERMAN, H. A. Study of the types of bacterial in bovine semen and their effect upon motility. Journal of Dairy Science, v.31, p.681, 1948. 
FENG, P. Escherichia coli Serotype 0157:H7 Novel vehicles of infection and emergence of phenotypic variants. Emerging Infectious Diseases, v.6, p.530-533, 2000.

IGUMA, L.T.; PIVATO, I.; CAMARA, J.U.; DAMATO, J.; PEREIRA, D.C.; CORREA, G.A.; MACHADO, G.M.; FRANCO, M.M.; BORGES, J.R.J.; RUMPF, R. Efeitos da administração de FSH em novilhas doadoras de ovócitos para a transferência nuclear usando fibroblastos de vaca crioula Junqueira - resultados preliminares. Acta Scientiae Veterinariae, v.173, p.35-54, 2005.

JASMIN.; POLISSENI, J.; TORRES-JUNIOR, J.R.S.; SÁ, W.F.; CAMARGO, L.S.A.; FERREIRA, A.M.; FOLHADELLA, I.M.; VIANNA, J.H.M.; RAMOS, A.A. Desenvolvimento in vitro de embriões derivados de oócitos bovinos maturados em meio sem controle da atmosfera gasosa. Acta Scientiae Veterinariae, v.33, p.376, 2005.

KNUTTON, S. Electron microscopical methods in adhesion. Methods Enzymology, v.253, p.145-158, 1995.

MAGAJEVSKI, F.S.; GIRIO, R.S.J.; MEIRELLES, R.B. Pesquisa de leptospira em fetos de vacas abatidas no estado de São Paulo, Brasil. Arquivos do Instituto Biológico, v. 74, n. 2, p. 67-72, 2007.

MARTINS JUNIOR, A.; CALEGARI, R.S.; FREITAS, C.P; ZANON, J.E.O.; PASCHOAL, D.M. Desenvolvimento potencial de embriões bovinos após fertilização de ovócitos in vitro com catalase e GnRH. Acta Scientiae Veterinariae, v.32, p.92, 2004.

MIYASHIRO, S.; CARVALHO, A.F.; NASSAR, A.F.C.; BALDASSI, L. Caracterização molecular e fenotípica de estirpes de Escherichia coli produtoras de shiga-toxina (STEC) não-0157 de amostras isoladas de fezes e carcaças bovinas. In: CONGRESSO BRASILEIRO DE MICROBIOLOGIA, 25., 2009, Porto de Galinhas, PE. , 2009. Disponível em: <http://sbmicrobiologia.org.br/PDF/cdsbm/ resumos/R0307-2.html>
PADRÓN, T.S. Técnicas de imunocitoquímica. In: Técnicas básicas de Microscopia Eletrônica aplicadas às Ciências Biológicas. Rio de Janeiro: UENF, 1998. p. 104-105.

PFEIFER, L.F.; SCHNEIDER, A.; CASTILHO, E.M.; LUZ, E.M.; ATHAIDE, P.F.; DIONELLO, N.J.L.; PIVATO, I.; RIMPF, R.; CORREA, M.N. Efeito da progesterona exógena em vacas doadoras de ovócitos sobre o desenvolvimento folicular e a produção in vitro de embriões. Acta Scientiae Veterinariae, v.33, p.184, 2005.

PICCOLOMINI, M.M.; GOES, A.C.; MIYASHIRO, S.; PAVÃO, D.L.; D'ANGELO. M. Desenvolvimento de embriões murinos in vitro infectados experimentalmente pela Escherichia coli produtora da toxina shiga stx 1. Biológico, v.70, n.2, p.107-216, 2008.

SALIBA, W.P.; ALVIN, M.T.T. Problemas relacionados a produção comercial de embriões bovinos. Acta Scientie Veterinariae, v.33, supl. 1, p.162-166, 2005.

STRINGFELLOW, J.S.; HATHCOCK, T.L;; RIDDEL, K.P.; STRINGFELLOW, D.A.; GALIK, P. K.; RIDDEL JR, M.G.; CARSON, R.L. Introduction of stenotrophomas maltophilia through semen used for in vitro production of bovine embryos Theriogenology, v.47, p.382, 1997.

STRINGFELLOW, D.A.; GIVENS, M.D. Infectious agents in bovine embryo production: hazards and solutions. Theriogenology, v.53, p.85-94, 2000.

STRINGFELLOW, D.A.; GIVENS, M.D. WALDROP, J.G. Biosecurity issues associated with current and emerging embryo technologies. Reproduction, Fertility and Development, v.16, p.93-102, 2004.

VARMA, J.K.; GREENE, K.D.; RELLER, M.E; DE LONG, S.M.; TROTTIER, J.; NOVICKI, S.F.; DI ORIO, M.; KOCK, E.M.; BANNERMAN, T.M.; YORK, S.T.; LAMBERT-FAIR, M.; WELLS, J.G.; MEAD, P.S. Outbreak of Escherichia coli 0157 infection following exposure to a contaminated building. Jama, v.290, p.2790-2712, 2003. 